\title{
El fitoplàncton dels aiguamolls de Ca l'Estany de Tordera (Barcelona)
}

\author{
- SERGI SABATER \& FRANCESC SABATER
}

\begin{abstract}
SABATER, S. \& F. SABATER (1987). The phytoplancton of the Ca l'Estany marshes at Tordera (Barcelona). Collect. Bot. (Barcelona) 17(1): 11-19.

The Ca l'Estany at Tordera, Barcelona (Maresme, Catalonia) are highly fluctuating marshes linked to the regime of the La Tordera river. Seventy-one species and varieties have been identified; their seasonal and local community variations are described.
\end{abstract}

Keywords: Phytoplankton, Ecology, Catalonia.

\section{Resum}

SABATER, S. \& F. SABAter (1987). El fitoplàncton dels aiguamolls de Ca l'Estany de Tordera (Barcelona). Collect. Bot. (Barcelona) 17(1): 11-19.

Els aiguamolls de Ca l'Estany de Tordera (Maresme, Catalunya) són sistemes força fluctuants, lligats al règim del riu La Tordera. Han estat determinades un total de 71 espècies $\mathrm{i}$ varietats en el fitoplàncton, de les que són descrites les seves variacions estacional i de comunitat segons les localitats.

Mots clau: Fitoplàncton, Ecologia, Catalunya.

\section{INTRODUCCIÓ}

Al nostre país, malhauradament, les zones humides mai no han estat especialment abundants i extenses. La dèria de dessecar-les ha estat constant des de sempre. El desembre de 1981 bona part d'aquests aiguamolls foren dessecats, i alguna de les localitats que aquí s'estudien ja no existeixen. Hi ha doncs, un interès doble a l'hora d'exposar aquest treball: un que n'és testimonial, i l'altre que contribueix al coneixement biològic d'una de les nostres zones humides.

Precisament, és remarcable el desconeixement que es té de les comunitats planctòniques dels nostres ambients aquàtics de petites dimensions. Des dels treballs clàssics de MARGALEF $(1951,1955,1958)$, poques dades noves es tenen. 
Aquest treball complementa, amb les dades del fitoplàncton, el coneixement de les comunitats zooplanctòniques d'aquest mateix indret (SABATER, 1982, 1983), amb el qual es pot obtenir una visió general del plàncton d'aquests aiguamolls.

\section{ZONA D'ESTUDI}

Els aiguamolls de Ca l'Estany de Tordera estan situats a la part baixa del curs de la Todera, a uns cinc quilòmetres de la desembocadura del riu i a dos de la població de Tordera (el Maresme, Barcelona).

Es tracta d'una depressió situada en una de les terrasses al-luvials del riu. Durant els mesos d'octubre a juny es produeix un aflorament d'aigües que pertanyen al nivell freàtic de la Tordera. Així, les característiques hidrològiques dels aiguamolls estan en funció del règim del riu; per això, totes les zones situades per sota o al mateix nivell que la cota del riu, són susceptibles d'inundació. Altrament, com que la Tordera té un règim marcadament mediterrani, amb un fort estiatge durant els mesos de juliol i agost, els aiguamolls experimenten una notable secada. Tanmateix, aquesta secada és diferencial segons uns llocs o altres, de manera que es pot parlar de tres hàbitats diferents, que es corresponen amb els llocs mostrejats (figura 1):

- llacuna o bassa gran, indret d'aigües quasi permanents, ja que es troba a una cota per sota de la del llit del riu, que antigament fou excavada per extreure'n argila. La superficie és d'uns 500 metres quadrats, amb una fondària màxima de $1,5 \mathrm{~m}$ de gener a abril, i mínima de 50 $\mathrm{cm}$ durant l'estiu. El sediment és negrós i poc compactat, i revela una gran acumulació de matèria orgànica.

La resta de les zones mostrejades es caracteritza per la seva temporalitat, ja que estan situades en aquelles terres que es troben a una cota igual o lleugerament inferior que la del nivell del riu. Són de dos tipus:

- Canals. Són construïts d'antuvi pels propis pagesos per tal d'afavorir el drenatge dels camps de conreu que queden inundats. Tenen una fondària mitjana de $80 \mathrm{~cm}$ i una amplada de $150 \mathrm{~cm}$. Resten inundats de novembre fins a la meitat de juny.

- Prats inundats. Són les zones que pateixen més intensament les variacions de cabal del riu. El nivell d'inundació és d'uns $25 \mathrm{~cm}$ com a màxim. Aquest fet, junt amb el curt període en què els prats estan inundats - de gener a abril-dificulta en gran mesura l'estabilitat de les comunitats d'organismes que s'hi desenvolupen (SABATER, 1983, 1984).

Els macròfits es desenvolupen de manera important en aquest sistema d'aiguamolls. A la llacuna, s'hi fan les comunitats de Potamogetum denso-nodosi al litoral i Lemno-Azolletum al mig. Als canals, durant la primavera, hi dominen els macròfits Ranunculus fluitans i Callitriche polymorpha. Als prats hi resta una comunitat pròpia de prats humits i jonqueres, amb Juncus effusus, Eleocharis palustris i Trifolium pratense.

\section{CARACTERÍSTIQUES FÍSICO-QUÍMIQUES DE LES AIGÜES}

Si haguéssim de caracteritzar breument les aigües d'aquests aiguamolls des del punt de vista químic, la paraula més adient seria la inestabilitat, la variabilitat en el temps.

La mineralització és força elevada (conductivitats de 700 a $1.200 \mu \mathrm{S}$ ), i tendeix a augmentar a mesura que s'assequen les zones. Els valors de l'alcalinitat són en terme mitjà moderats (4 meq/l a la llacuna, $3 \mathrm{meq} / 1$ a la resta de llocs), però ocasionalment, són més elevats (7.7 meq/l a la llacuna durant la primavera) o força baixos ( $2.2 \mathrm{meq} / 1$ als canals durant la tardor). Els clorurs són sempre baixos, a l'igual que els sulfats (1.7 - $6.2 \mathrm{meq} / 1$ de mitjana pels primers, de 3 a $6 \mathrm{meq} / 1$ pels segons). 


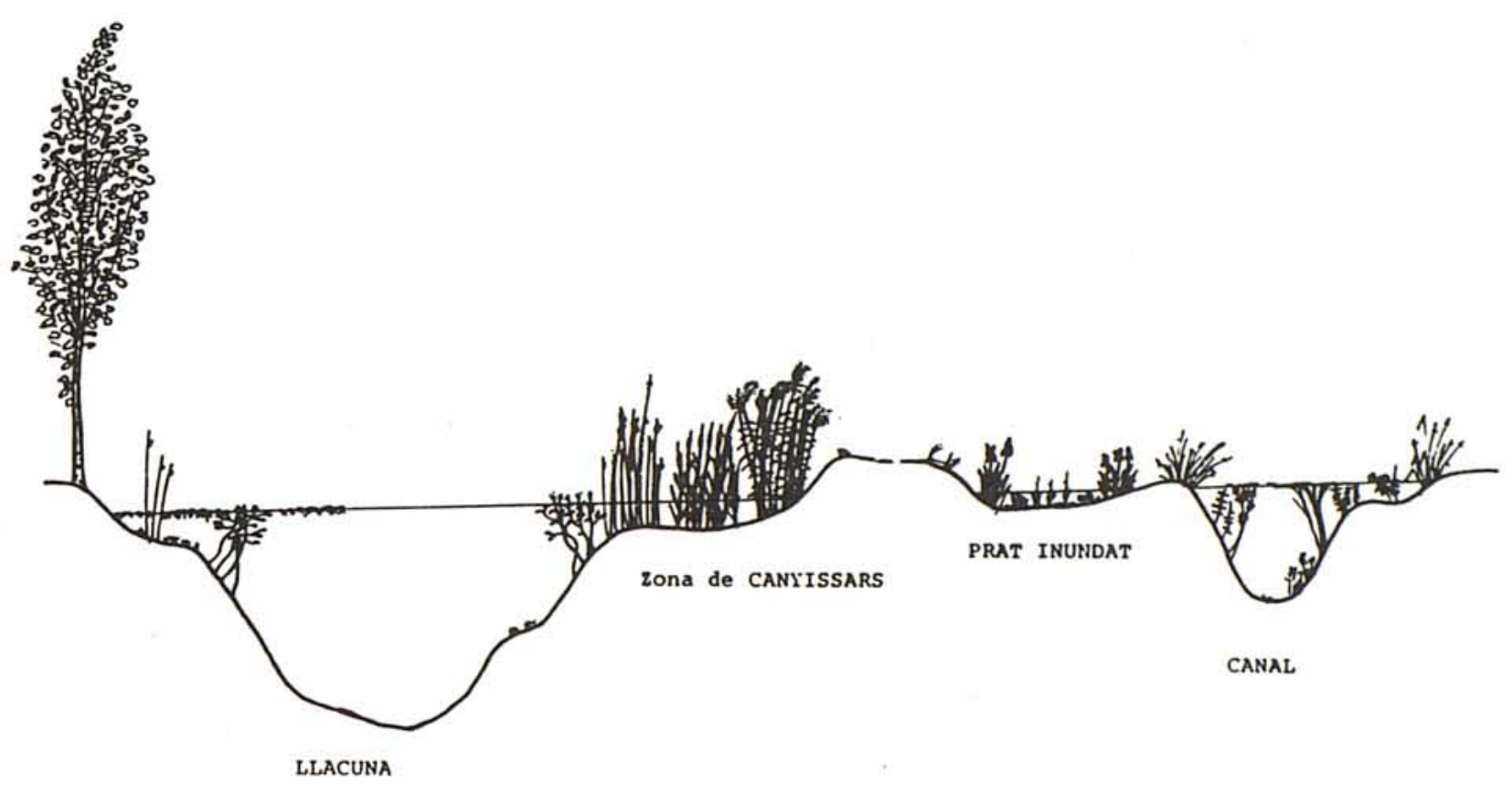

Fig. 1.- Esquema dels diferents hàbitats mostrejats als aiguamolls de Ca l'Estany (Tordera).

En general, el prat, quan es compara amb la resta de zones, té uns paràmetres de mineralització molt fluctuants en el temps. En canvi, la llacuna i els canals no presenten massa variació durant la inundació, però no així quan comencen a assecar-se, moment en què augmenten considerablement.

Pel que fa als nutrients, els seus valors varien molt segons l'època de l'any i la zona en qüestió, i, a l'ensems, són força elevats, la qual cosa ocasiona que la producció fitoplanctònica sigui també intensa. Durant l'hivern, els valors de fostat reactiu soluble eren moderats, al voltant de $2.5 \mu \mathrm{gr}$-at $\mathrm{P} / \mathrm{l}$. Els valors de nitrats eren molt variables, des de $0.5 \mu \mathrm{gr}$-at $\mathrm{N} / \mathrm{l}$ als prats inundats i uns $8 \mu \mathrm{gr}$-at N/1 a la llacuna, fins a uns $300 \mu \mathrm{gr}-\mathrm{at} \mathrm{N} / \mathrm{l}$ als canals. Els valors tan marcadament elevats al canal s'expliquen per la funció que tenen de recollir les aigües dels camps de conreu, que són força adobats.

En canvi, durant la primavera i l'estiu, moment en què els productors primaris assolien el seu màxim, es registrava un excés de fostats, de l'ordre de $14 \mu \mathrm{gr}$-at P/l, i un exhauriment dels nitrats, tant en el prat com en la llacuna. Aquest és un comportament propi d'un ecosistema forçat: de fet, la descomposició en aquella època era força elevada, per la quantitat de matèria orgànica acumulada. Aquesta situació s'agreujà, fins que, a finals d'estiu es produí una situació d'anaerobiosi.

Cal remarcar també que en aquests aiguamolls és ben palesa l'abundància de ferro en alguns indrets, manifesta en els precipitats marronosos que apareixen en el sediment.

\section{MATERIAL I MÈTODES}

Les mostres de fitoplàncton foren agafades mensualment durant l'hivern de 1980, i quinzenalment durant la primavera i començaments d'estiu de 1981. Una altra mostra va ser presa, de manera extensiva, el 27-1-1985. Els llocs mostrejats són els ja descrits: llacuna, canals i prats inundats.

Les mostres van ser agafades amb salabrets de 40 o de $60 \mu \mathrm{m}$ de porus i, ocasionalment, amb flascons de vidre de $250 \mathrm{ml}$. Aquestes últimes mostres van ser fixades amb lugol i 
deixades sedimentar, s'observaren després amb microscopi invertit. La resta fou fixada amb formol al 4 per cent, i es tenyí amb lugol per a observar possibles formacions de midó.

Per a la determinació de les espècies es seguí DESIKACHARY, 1958 i GEITLER, 1932 per a les cianoficies, HubER-PESTALOZZI, 1955-1961 per a les euglenals i les volvocals, KOMAREK \& FOTT, 1983 per a les clorococcals, ETTL, 1978 per a les xantofícies, GEMENHARDT, 1939 per a les oedogonials, RAMANATHAN, 1964 per a les ulotricals, RANDHAWA, 1959 per a les zignemàcies i WEST \& WEST, 1904-1922 per a les desmidiàcies.

\section{CATÀLEG FLORÍSTIC DE LES ESPÈCIES}

En aquest apartat figuren les espècies de fitoplàncton -0 associades a ell-determinades a Ca l'Estany. S'hi indica per a cada una el lloc concret en què era trobada i l'època, així com les mesures de les cèlllules de les espècies menys freqüents.

\section{BACTERIA}

Sphaerotilus natans (Cohn.) Misg. Present únicament a la llacuna durant la fi de la primavera, en poca quantitat.

\section{CYANOPHYCEAE}

Microcystis pulvurea v. incerta Lemm. Ocasional. Cèl-lules de 1,5 $\mu \mathrm{m}$ de diàmetre, colònies de $100 \mu \mathrm{m}$.

Anabaena constricta (Szafer) Geitler. Ocasional. Cèl-lules de 6-7,5 $\mu \mathrm{m}$ de diàmetre, heterocist de $7,5 \times 5 \mu \mathrm{m}$; no es va observar acinets.

Nostoc planctonicum W. Poretz \& Tschern. Freqüent algun cop al prat. Cèl-lules de $5 \mu \mathrm{m}$ de diàmetre, heterocist de $10 \mu \mathrm{m}$ de diàmetre. Colònies de grandària variable, des de 175 fins $950 \mu \mathrm{m}$.

Tolypothrix distorta Kütz. Abundant en el prat, a finals de primavera. Cèl-lules de $9 \times 5,5 \mu \mathrm{m}$, heterocists de $9 \times 11 \mu \mathrm{m}$.

Stigonema hormoides (Kütz.) Bornet \& Flah. Ocasional. Cèl-lules de 5-7,5 $\mu \mathrm{m}$ de diàmetre.

Oscillatoria limosa Ag. ex Gom. Present a la llacuna, de forma constant, però sempre en poca quantitat.

Schizothrix sp. Ocasional. Filaments de 1,5 $\mu \mathrm{m}$ d'amplada; beina taronjada, d'uns $15 \mu \mathrm{m}$ de diàmetre.

\section{EUGLENOPHYCEAE}

Euglena spirogyra Ehr. Ocasional, a la llacuna.

Euglena sp. Dimensions, 12-12,5 × 30-40 $\mu \mathrm{m}$.

\section{DINOPHYCEAE}

Peridinium cinctum (Müll.) Ehr. Abundant al prat, durant l'hivern. 

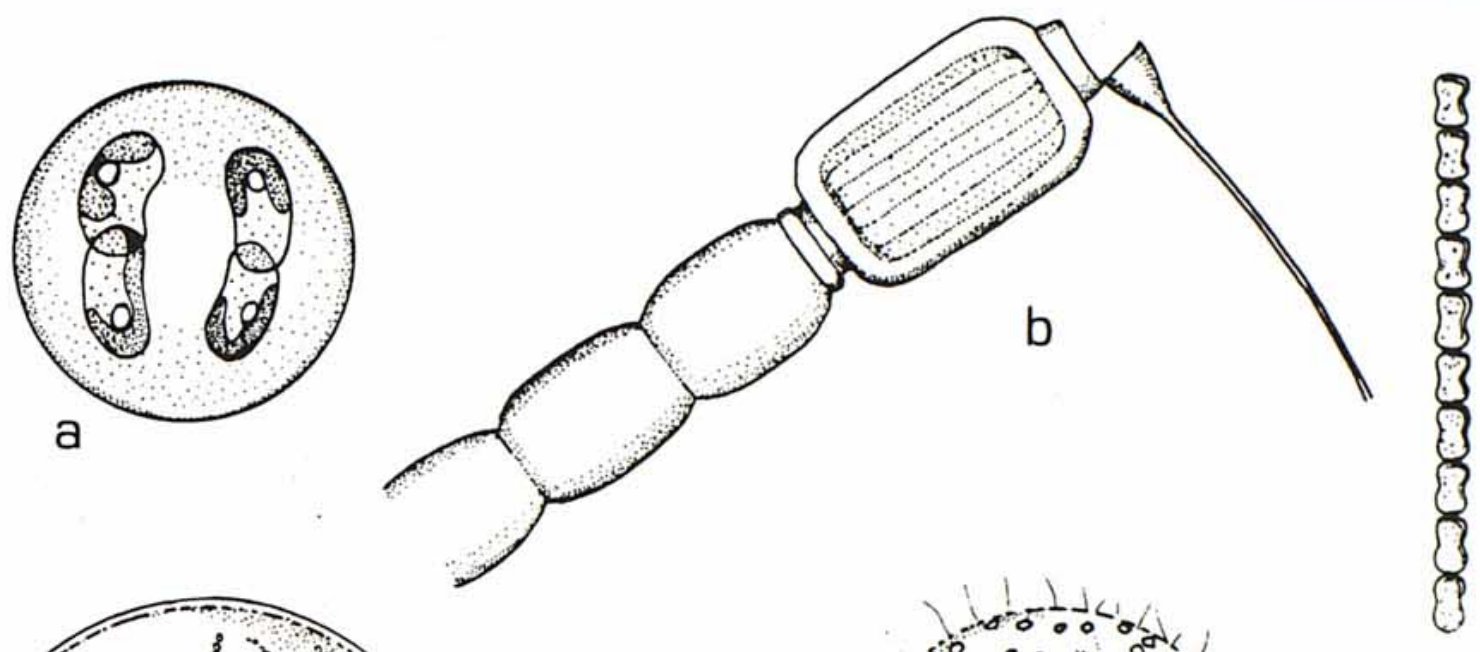

C

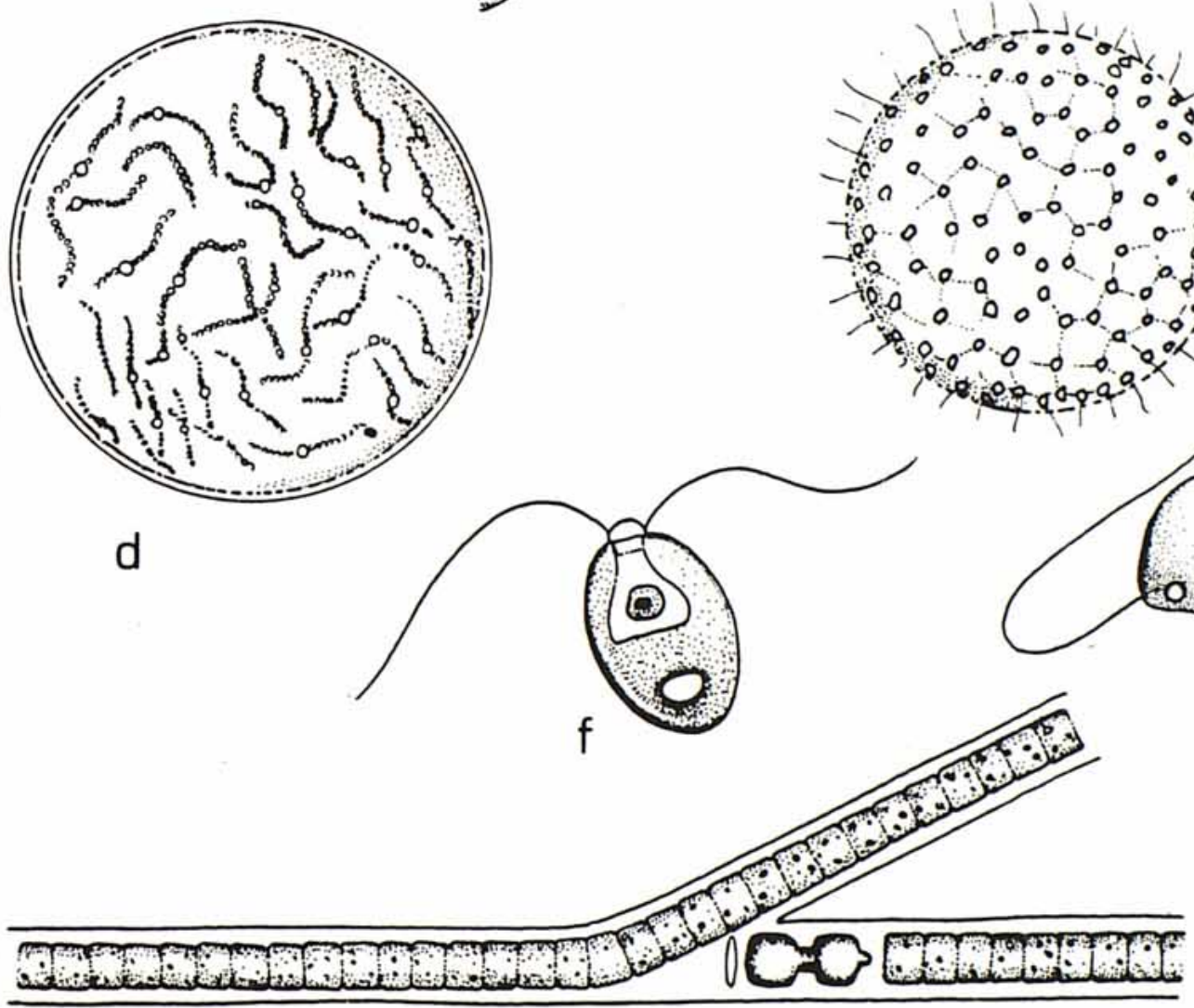

g
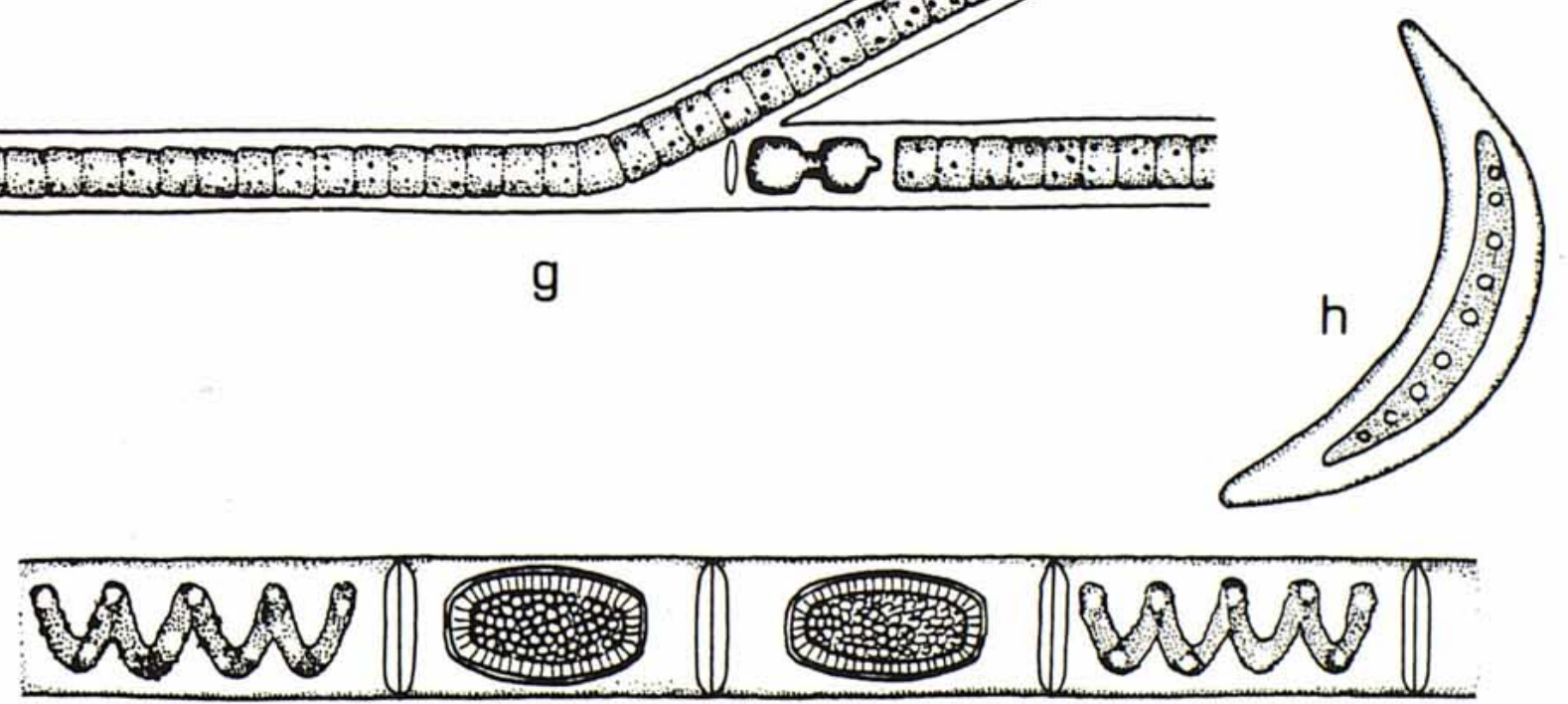

i

Fig. 2.- a) Nephrocyctium agardhianum; b) Bulbochaete megastoma, part terminal i oogoni; c) Anabaena constricta; d) Nostoc planctonicum, colònia; e) Sphaeroeca volvox, e') cèl-lula; f) Chlamydomonas debaryana; g) Tolypothrix distorta; h) Closterium moniliferum; i) Spirogyra dentireticulata.

a), b), c), e), f), i) a $400 \mathrm{x}$; d), a $100 \mathrm{x}$; e') a $1.000 \mathrm{x}$; g), a $200 \mathrm{x}$. 


\section{CHRYSOPHYCEAE}

La major part d'elles es trobaren en una petita llacuna amb precipitats ferruginosos, no inclosa dins els mostreigs periòdics, i durant l'hivern.

Dinobryon sertularia Ehr. Rara.

Uroglena conradii Schiller. Ocasional. Cèl-lules de 9,5×12 $\mu \mathrm{m}$.

Sphaeroeca volvox Ltb. Rara. Cèlllules de 13-14 $\mu \mathrm{m}$ de diàmetre; colònies de $130 \mu \mathrm{m}$.

Chrysocapsa planctonica Pascher. Molt abundant durant l'hivern al prat i al canal. Cèl-lules de 5-6 $\mu \mathrm{m}$; colònies de 20-150 $\mu \mathrm{m}$ de diàmetre.

\section{CHLOROPHYCEAE}

Chlamydomonas debaryana Gor i la seva varietat atactogama (Korsch.) Gerloff., és una espècie molt abundant durant l'hivern en els tres hàbitats mostrejats.

Ankistrodesmus falcatus (Corda) Ralfs. Ocasional.

Nephrocyctium agardhianum Nägeli. Ocasional. Cèl-lules de $6,5 \times 9 \mu \mathrm{m}$; colònies de $19 \mu \mathrm{m}$ de diàmetre.

Oedogonium crispum f. granulosum (Nordsted) Hirn. Espècie present en les tres zones estudiades. A la primavera assolí un creixement gran i fructificà. Cèl-lules de $20 \times 80 \mu \mathrm{m}$; oogoni de 40-50 $\mu \mathrm{m}$ de diàmetre.

Oedogonium sp. Distribució semblant a l'anterior, però menys abundant. Cèlllules de $17 \times 65$ $\mu \mathrm{m}$.

Bulbochaete megastoma Wittrock \& Lundell. Espècie trobada solament en el prat, de forma ocasional. Fructificà durant la primavera. Cèl-lules de 17,5 $\times 26 \mu \mathrm{m}$. Oogoni de $56 \times 32 \mu \mathrm{m}$.

Bulbochaete sp. Ocasional. Cèl-lules de $16 \mu \mathrm{m}$ d'amplària per 28-32 $\mu \mathrm{m}$ de llargària.

Aphanochaete sp. Ocasional. Epífit sobre Mougeotia i Tribonema. Cèlllules de 6,5-10 $\mu \mathrm{m}$ de diàmetre.

Draparnaldia glomerata Ag. Ocasional, al canal.

Hydrodiction reticulatum (L.) Lagerh. Ocasional, al prat.

Microspora amoena (Kütz.) Rabh. és especialment freqüent durant l'hivern i principis de primavera, acompanyant a Tribonema. La forma més freqüent és la corresponent a la varietat gracilis (Wille) de Toni, més estreta i petita (cèlllules de $16 \mu \mathrm{m}$ de diàmetre).

Microspora sp. Ocasional. Cèlllules de 6,5 $\mu \mathrm{m}$ de diàmetre.

Ulothrix tenerrima (Kütz.) Kütz. Ocasional. Espècie molt semblant a $U$. variabilis, citada per MARGALEF (1958) com a freqüent en aquestes comunitats planctòniques, però és de dimensions més reduïdes que ella (Cèlllules de $12 \times 10 \mu \mathrm{m}$ ).

Cladophora glomerata Ag. Ocasional. Foren trobades branques velles a la llacuna, probablement arrossegades.

Sphaerocystis schroeteri Chod. Freqüent al canal. Colònies de 45-150 um; diàmetre de les cèl-lules de 5 a $12 \mu \mathrm{m}$.

\section{ZYGOPHYCEAE}

Mougeotia scalaris Hassall. Abundant a la llacuna durant la primavera. Les cèl-lules vegetatives són de 27-29 $\mu \mathrm{m}$ d'amplada, i de 3 a 5 vegades més llarges. Zigòspora de $30 \times 42 \mu \mathrm{m}$.

Spirogyra paludosa Czurda. Freqüent al canal durant la primavera. Cèl-lules de $25 \mu \mathrm{m}$, de 2 a 3 vegades més llargues. Gametangi $50 \mu \mathrm{m}$ de diàmetre; Zigòspora de $22 \mu \mathrm{m}$ de diàmetre.

Spirogyra dentireticulata Jao. Espècie ocasional. Cèl-lules vegetatives de $30 \mu \mathrm{m}$, de 1 a 2 vegades més llarges; zigòspora de $30 \mu \mathrm{m}$ de diàmetre. 
Spirogyra spp. Són freqüents en tots els hàbitats, sobretot durant la primavera.

Zygnema vaginatum Klebs. Espècie molt abundant al canal $\mathrm{i}$ al prat, a la primavera. Cèl-lules de $28 \times 35 \mu \mathrm{m}$; zigòspora de $28 \mu \mathrm{m}$ de diàmetre.

Closterium parvulum Näg. Ocasional. Cèl-lules de $100 \times 12 \mu \mathrm{m}$.

Closterium acerosum (Schrank.) Ehr. Espècie present en els tres hàbitats estudiats. Exemplars de $15-19 \times 300-370 \mu \mathrm{m}$.

Closterium moniliferum (Bory) Ehr. Freqüent als tres hàbitats.

Closterium kutzingii Breb. Ocasional.

Staurastrum punctulatum Breb. Ocasional.

Cosmarium botrytis Menegh. Freqüent al prat, durant tot l'any. Cèl-lules de $57 \times 75 \mu \mathrm{m}$; itsme de $17,5 \mu \mathrm{m}$.

Pleurotaenium truncatum (Breb.) Näg. Freqüent, al prat. Cèl-lules de $280 \times 50 \mu \mathrm{m}$.

\section{XANTHOPHYCEAE}

Vaucheria sp. Recobria zones molt somes a la vora de la llacuna, on era dominant, constituint l'herpon i el bentos. Algunes branques eren trobades en el plàncton. Les branques velles tenien incrustacions de ferro i duien abundants epífits, principalment clorococals.

Tribonema viride Pasch. Espècie dominant durant l'hivern en els tres hàbitats.

Tribonema minus (Klebs) Hazen. Acompanyant de l'espècie anterior, sempre aparegué en menor quantitat.

Ophiocyctium cochleare (Eichwald) A. Br. Ocasional.

Ophiocyctium arbusculum (A. Br.) Rabh. Ocasional.

\section{BACILLARIOPHYCEAE}

Melosira varians C. A. Ag. Aparegué en masses al canal, durant l'hivern i la primavera.

Fragilaria virescens Ralfs. A l'hivern fou l'alga dominant en el plàcton del canal, desplaçant a Tribonema.

Fragilaria intermedia Grun. Freqüent al canal durant l'hivern, formant cintes de grandària reduïda.

Synedra ulna (Nitzsch). Ehr. Freqüent en els tres hàbitats, arribà a ser molt important als canals durant la primavera.

Synedra acus Kütz. Ocasional. formant colònies.

Epithemia turgida (Ehr.) Kütz. Epífita sobre Tribonema.

Rhopalodia gibba (Ehr.) Mill. Epífita sobre Mougeotia.

Eunotia pectinalis (Kütz.) Rabh. Epífita damunt Mougeotia i Oedogonium. Freqüent en els tres hàbitats.

Altres espècies de diatomees aparegueren formant part del perifiton de les algues filamentoses, sobretot als canals, i durant l'hivern:

Pinnularia viridis (Nitzsch.) Ehr.

Cocconeis placentula (Ehr.) $\mathrm{Cl}$.

Cymatopleura solea (Breb.) W. Smith

Stauroneis phoenicentron Ehr.

Surirella linearis W. Smith

Surirella ovata Kütz.

Frustulia vulgaris Thwaites.

Gomphonema constrictum Ehr.

Gyrosigma acuminatum (Kütz.) Rabh. 
Nitzschia gracilis Hantzsch.

Nitzschia pusilla Kütz.

Nitzschia palea (Kütz.) Grun.

Gomphonema intricatum v. pumila Grun.

Amphora pediculus Kütz.

Meridion circulare Agardh

\section{DISCUSSIÓ}

Els aiguamolls de Ca l'Estany de Tordera - a l'igual que succeeix en ecosistemes semblants- són força inestables, a causa de les variacions en el seu règim.

Aquesta inestabilitat és el determinant de les comunitats que s'hi fan. Es tracta de comunitats d'algues filamentoses que es desenvolupen a pulsos. Als tres llocs estudiats -llacuna, canals, prats inundats - tenen uns trets comuns, tant en la seva composició d'espècies com en els canvis que experimenten en el temps. A l'hivern, Tribonema era l'alga pionera, acompanyada en menor proporció per Oedogonium, cobrint de color verd clar la superficie de l'aigua. Solament al canal, les diatomees filamentoses -Melosira varians, Fragilaria virescens i Fragilaria intermedia-trenquen l'homogeneïtat i es desenvolupen en masses, acompanyades per alguna epífita, com Eunotia pectinalis i Rhopalodia gibba.

Amb l'arribada de la primavera, aquesta comunitat es complementava amb un bon grup de zignemals -Spirogyra spp., Mougeotia spp., Zygnema spp.-, i es feia més diversa. En aquestes condicions, s'arribava fins al període de secada - en els canals i en els prats- $\mathrm{o}$ al moment en què els macròfits desplaçaven el fitoplàncton -a la llacuna-.

En alguns clots inundats foren trobades -sobre substrats rics en ferro- espècies de crisoficies i Vaucheria. Això ve a remarcar la descripció que feu MARGALEF (1958) d'aquestes comunitats, que ell anomenà Tribonemetum siderophilum. Amb l'ànim de tipificar els aiguamolls, podríem dir que les llacunes i els prats inundats formen part d'aquesta associació, mentre que els canals, on l'aigua té un cert moviment, serien una associació diferent, Eunotieto-Fragilarietum.

\section{AGRAÏMENTS}

Els Drs. Joan Armengol i Ramon Margalef han revisat el manuscrit i han fet nombroses suggerències. En Miquel Zabala ha fet els dibuixos de les espècies d'algues. A tots ells, el nostre sincer agraïment.

\section{BIBLIOGRAFIA}

DesiKachary, T. V. (1959). Cyanophyta. Indian Counc. Agric. Res. New Delhi. 686 pls.

ETTL, H. (1978). Xanthophyceae. Susswasserflora von Mitteleuropa. Gustav Fischer Verlag. Stuttgart, 530 pls.

GeITLER, L. (1932). Cyanophyceae. Rabenhorst's Kryptogamen Flora. Akadem. Verlags. Leipzig. 1.196 pls.

GemenhardT, K. (1939). Oedogoniales. Rabenhorst's Kryptogamen Flora. Akadem. Verlags. Leipzig. 453 pls.

Huber-Pestalozzi, G. (1955-1961). Euglenophyceae, Chlorophyceae (Volvocales). Phytoplankton das Susswassers, 4-5. Stuttgart.

Komarek, J. \& FotT, B. (1983). Chlorophyceae (Chlorococcales). Phytoplankton das Susswassers, 7, 1. Stuttgart, 1.044 pls. 
MARGALEF, R. (1951). Regiones limnológicas de Cataluña y ensayo de sistematización de las asociaciones de algas. Collect. Bot. (Barcelona) 3(1): 43-67.

MARGALEF, R. (1955). Organismos indicadores en la limnología. Inst. Forestal Invest. Exper. Madrid.

MARGALEF, R. (1958). Materiales para el estudio de las aguas dulces y salobres, principalmente del NE de España. Publ. Inst. Biol. Apl. 28: 5-47.

Ramanathan, K. R. (1964). Ulothrichales. Ind. Counc. Agr. Res. New Delhi. 188 pls.

Randhawa, M. S. (1959). Zygnemaceae. Ind. Counc. Agr. Res. New Delhi. 478 pls.

SABATER, F. (1982). Les comunitats de crustacis dels aiguamolls de Ca l'Estany de Tordera. Estudi limnològic. Tesi de llicenciatura. Barcelona.

SABATER, F. (1983). Comunidades de crustáceos de las lagunas de Tordera (Barcelona), en relación con sus características ambientales. Actas I Congr. Esp. Limnologia: 23-33.

WeSt, W. \& WEST, G. S. (1904-1922). A Monograph of the British Desmidiaceae. Jonhson Reprint Corp. (1971). London. 